\title{
Evolução do nível de compreensão do jogo Quoridor: uma comparação entre idosas e adolescentes
}

\author{
Evolution of the comprehensive level of the Quoridor game: a comparison \\ between elderly women and adolescents

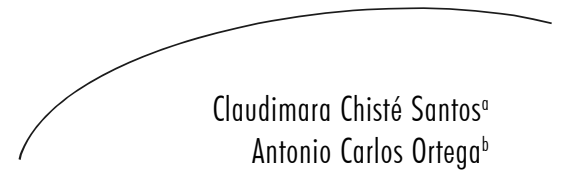

\section{Resumo}

Os aspectos cognitivos relacionados ao envelhecimento precisam ser mais investigados, tendo em vista a necessidade de criar estratégias de prevenção ou manutenção de uma velhice saudável e ativa. Esta pesquisa teve por objetivo comparar a evolução do nível de compreensão de um jogo de regras entre idosas e adolescentes. Foram constituídos dois grupos de quatro participantes para cada faixa etária: um de 65 a 75 anos e outro de 16 a 17 anos. Como referencial, foi utilizada a teoria de Piaget. O instrumento de investigação foi o jogo Quoridor. Ao longo de quatro etapas, as participantes tiveram a oportunidade de jogar entre adversárias de mesma faixa etária, além de serem entrevistadas individualmente para se posicionarem diante de situações-problema. Os critérios de análise foram estabelecidos a partir de níveis de compreensão do jogo - do menor para o maior: I, II/A, II/B, III/A, III/B. Os resultados indicam que duas idosas e duas adolescentes alcançaram nível II/B; uma idosa não evoluiu no nível de compreensão, ficando no nível I; duas

Palavras-chave: envelhecimento/ Psicologia; prevenção primária; idoso; mulheres; adolescente; jogos experimentais; estudo comparativo adolescentes atingiram o nível II/B e uma idosa o nível III/A. Desta forma, o nível mais alto foi alcançado por uma idosa, contrariando o pressuposto de que o declínio cognitivo é inevitável em idosos jovens, e que um idoso sempre terá desempenho pior que um adolescente. Em se tratando de aspectos cognitivos, muitos são os fatores envolvidos, e apenas a faixa etária não garante uma previsão do quanto um sujeito pode se desenvolver.

\footnotetext{
Universidade Federal do Espírito Santo

Programa de Pós-Graduação em Psicologia

Vitória, ES, Brasil

Correspondência / Correspondence

Claudimara Chisté Santos

Rua Natalina Daher Carneiro, 860/204

29060-490 - Vitória, ES, Brasil

E-mail: claudimarachiste@uol.com.br
} 
Abstract

The cognitive aspects related to ageing need a more thorough investigation, in view of the need of creating preventive or maintenance strategies for an active and healthy ageing. This research aimed to compare the evolution of the comprehension level of a game of rules between elderly women and adolescents. Two groups of four participants for each age group were formed: one aged 65-75 years, and the other, 16-17 years. The study was based on Piaget's theory. As an instrument for investigation, the Quoridor game was used. Throughout four stages, the participants had the opportunity to play amongst adversaries of the same age group, besides being individually interviewed so as to position themselves before problem-situations. The analysis criteria were established from levels of comprehension about the game - from the lowest to the highest one: I, II/A, II/ B,III/A,III/B. Results indicated that two elderly women and two adolescents reached the II/B level; an elderly woman did not evolve on the comprehension level, remaining on level I; two adolescents reached the II/B level, and an elderly woman, the III/A. Thus, the highest level was obtained by an elderly woman, contrary to the assumption that cognitive decline is inevitable among young elders, and that an elder shall always have a worse performance than that of an adolescent. When it comes to cognitive aspects, many are the factors evolved, and the age group alone does not guarantee just how much a subject may develop himself.

\author{
Key words: aging / \\ Psychology; primary \\ prevention; aged; \\ women; adolescent; \\ games experimental; \\ comparative study
}

INTRODUÇÃO

No estudo sobre o desenvolvimento humano, o envelhecimento tem sido cada vez mais analisado. $\mathrm{O}$ acréscimo gradual de tal interesse se deve, entre outros fatores, ao aumento da expectativa de vida, que gera impacto na economia e traz desafios para asáreas de saúde, trabalho, lazer e turismo. Segundo o IBGE, ${ }^{1}$ em 2050 os idosos serão um quinto da população mundial.

Ao se investigar o fenômeno do envelhecimento, é preciso considerar, entre outros aspectos, a cognição. Estudos sobre esse fenômeno corroboram o pressuposto de que o convívio social e hábitos saudáveis podem alterar o ritmo do declínio cognitivo.-14
Assim sendo, se tal declínio pode ser alterado, é preciso aprofundar o conhecimento sobre as estratégias eficazes para manter ou melhorar o raciocínio no envelhecimento.

O processo de desenvolvimento, tal como descrito por Piaget, ${ }^{15,16}$ é determinado por vários aspectos, tanto físicos quanto sociais. A partir deste pressuposto, é possível supor que a genética, o estímulo do meio externo, a qualidade de vida e a saúde influenciem diretamente na maneira como o indivíduo se desenvolve. Tais conjecturas sustentam os resultados da pesquisa que será aqui explanada.

OEstudo Longitudinal de Seatle ${ }^{17}$ trouxe contribuições para a questão do declínio cognitivo. Utilizando métodos longitudi- 
nais e transversais, o autor pesquisou indivíduos entre os anos de 1956 a 1991. A cada sete anos, eram introduzidos novos participantes na amostra e um dos objetivos era avaliar se havia declínio cognitivo em idosos. Ele concluiu que a partir dos 70 anos, em média, começa a haver um pequeno declínio de algumas habilidades, que se referem à aprendizagem em situações novas; outras, principalmente as habilidades que utilizam conhecimentos prévios, adquiridos ao longo da vida, tendem a se conservar na velhice, desde que não haja problemas de saúde significativos. Métodos de intervenção precisam ser adaptados e testados para identificar como manter ou melhorar tais habilidades no envelhecimento.

Matos ${ }^{18}$ realizou oficinas utilizando, inclusive, jogos de regras, da qual participaram 18 idosos. Ela menciona benefícios apontados na literatura, tais como estimulação da memória e possibilidade de associação das atividades com a realidade. Segundo a autora, o lúdico favorece a estimulação cognitiva e é um recurso que precisa ser adaptado para intervenções com idosos.

Foi realizado levantamento sobre trabalhos científicos com jogos de regras e constatou-se que são escassos os trabalhos com idosos. Além das bases de dados OVID, PsycINFO e SCIELO, foram utilizadas cinco fontes: (1) o trabalho de Rossetti e Souza ${ }^{19}$; (2) os seguintes sites: da Universidade Federal do Espírito Santo (http://www.ufes.br/ $\sim$ dpg/psicologia/egressos.htm); da Universidade de SãoPaulo (http://www.teses.usp.br/ biblioteca.html); da Unicamp (http:// www.unicamp.br/bc/) e da Coordenação de Aperfeiçoamento de Pessoal de Nível Superior (http://servicos.capes.gov.br/capesdw/); (4) artigos científicos; (5) capítulos e/ou livros.

Os dados demonstram que, dos estudos realizados com jogos de regras no Brasil, dos anos 1980 até 2006, foram encontrados: 19 trabalhos (42\%) realizados com crianças; 11 (24\%) com crianças e adolescentes; cinco (11\%) com adolescentes; um (2\%) com adolescentes e adultos; oito (18\%) com adultos; um (2\%) com adolescentes e idosos. O único trabalho com idosos que utiliza jogos de regras foi o realizado por Santos, Rossetti e Ortega, ${ }^{17}$ que serviu de base para a presente pesquisa. A maior parte dos trabalhos foi realizada com crianças e adolescentes até 13 anos.

Em se tratando de pesquisas gerais sobre envelhecimento no Brasil, foi realizado um levantamento pela Universidade do Estado do Rio de Janeiro, ${ }^{20}$ que identificou 144 grupos de trabalho no Brasil, 209 linhas de pesquisa e 511 pesquisadores atuantes na área do envelhecimento. Entre os temas pesquisados, os que surgem com maior percentual são: doenças crônicas e degenerativas (16,2\%), educação, promoção de saúde e prevenção de doenças (11\%) e envelhecimento biológico (10,7\%). Termos relacionados à cognição ou correlatos não foram citados nesse estudo. É provável que tenham sido considerados como subáreas não citadas ou então não foram realmente encontrados grupos de trabalho relacionados a esse tema.

Estudos sobre a memória são mais comuns quando o tema é cognição no enve- 
lhecimento, mas ainda assim há muito a esclarecer, como aponta Yassuda, ${ }^{21}$ que faz uma revisão de literatura indicando que no idoso saudável há possibilidade de compensação de déficits cognitivos.

Uma investigação exploratória sobre o nível de compreensão de um jogo de regras com idosos pode ampliar o conhecimento de suas habilidades em um ambiente lúdico. Como a caracterização de um fenômeno se torna mais completa se houver um grupo comparativo, foram selecionadas adolescentes para efeito de comparação com as idosas. Segundo Meltzoff, ${ }^{22}$ é necessário, em questões descritivo-comparativas, haver descrições tanto sobre semelhanças quanto sobre diferenças. Assim, é possível caracterizar cada um dos grupos de forma mais sistematizada e foi esta a razão para o grupo de adolescentes ser incluído.

O referencial utilizado neste estudo é a teoria de Piaget, que será abordada a seguir.

\section{O DESENVOLVIMENTO HUMANO NA PERSPECTIVA DE PIAGET}

Se para Piaget o desenvolvimento é eminentemente cognitivo (apesar de deixar claro o papel fundamental da afetividade nesse processo), é preciso buscar entender o desenvolvimento na ação própria do sujeito, e sua inter-relação com o objeto. Embora não se tenha encontrado nenhum estudo realizado por Piaget com idosos, ele coloca que "a equilibração cognitiva não marca jamais um ponto de parada, senão a título provisório". ${ }^{15}$ É possível supor, portanto, que mesmo depois de chegar ao estádio lógico-formal, a inteligência continua a progredir em relação aos aspectos funcionais.

Atividades complexas, como montar um quebra-cabeça ou ganhar um jogo de regras com um ou mais adversários, exigem várias ações coordenadas, ou seja, é na relação entre o fazer e o compreender que se constrói o pensamento. Segundo Piaget, ${ }^{23}$ "Fazeré compreender em ação uma dada situação em um grau suficiente para atingir os fins propostos, e compreender é conseguir dominar, em pensamento, as mesmas situacõoes até poder resolver os problemas por elas levantados, em relação ao porque e ao como das ligações constatadas e, por outro lado utilizadas na ação."

A observação da ação de participantes da pesquisa, bem como seus relatos sobre os procedimentos utilizados, permite analisar as intenções presentes em cada jogada.

A partir do posicionamento dos participantes, pode-se ter certeza de que o procedimento inferido de fato está presente na intenção do sujeito. Tal intenção só pode ser detectada por dois meios: a fala e a ação. Portanto, utilizou-se um jogo de regras que permitisse acompanhar o desempenho das participantes ao serem colocadas diante de desafios, ou situaçõesproblema.

Partindo dessas considerações, o objetivo geral desta pesquisa foi comparar a 
evolução do nível de compreensão de um jogo de regras entre idosas e adolescentes. Para alcançar tal propósito, foram estabelecidos os seguintes objetivos específicos: caracterizar a evolução do nível de compreensão do jogo Quoridor das idosas; caracterizar a evolução do nível de compreensão do jogo Quoridor das adolescentes; e comparar o nível de compreensão do jogo Quoridor alcançado pelas idosas e adolescentes.

\section{MÉTODO}

\section{Participantes}

Participaram desta pesquisa quatro idosas e quatro adolescentes do sexo feminino. O número reduzido de participantes justifica-se pela_característica exploratória do trabalho. Como já mencionado na revisão de literatura, há poucos estudos com idosos utilizando jogos de regras como instrumento, e tal escassez de informações impede a formulação de hipóteses. Além disso, o método clínico de Piaget exige um detalhamento que aponta o estudo de caso como sendo o mais adequado para atingir os propósitos de observação e análise das condutas.

O grupo das adolescentes foi composto por participantes com idade entre 16 e 17 anos, que cursavam o $1^{\circ}$ ano do ensino médio em uma escola pública estadual e estudavam na mesma sala de aula. A seleção delas foi realizada com base na demonstração do interesse em participar da pesquisa e no desempenho escolar (médio em relação aos outros alunos da classe).

O grupo das idosas, com idade variando entre 65 e 75 anos, foi composto por duas participantes que tinham concluído o ensino médio, uma o ensino fundamental $\mathrm{e}$ a outra, cursado até a $7^{\mathrm{a}}$ série do ensino fundamental. Todas participavam das atividades realizadas em um centro de convivência para a terceira idade, da Prefeitura $\mathrm{Mu}$ nicipal de Vitória.

A escola pública estadual em que as adolescentes estudavam e o centro de convivência freqüentado pelas idosas estão localizados no mesmo bairro, de classe média baixa da cidade de Vitória-ES.

Os procedimentos foram baseados nas normas referentes à realização de pesquisas envolvendo seres humanos, estabelecidas pela Resolução n ${ }^{\circ}$ 196/96, de 10 de outubro de 1996, do Conselho Nacional de Saúde $^{24}$ e na Resolução n ${ }^{0}$ 016/2000, do Conselho Federal de Psicologia. ${ }^{25}$ Os nomes utilizados são fictícios.

Instrumentos e procedimento

A pesquisa foi realizada em quatro etapas. Na primeira, foi utilizada uma entrevista semi-estruturada e, nas demais etapas, o instrumento foi o jogo Quoridor. 


\section{ETAPA 1}

Nesta etapa, realizou-se inicialmente uma entrevista com o objetivo de complementar as informações sobre as participantes:

\begin{tabular}{|c|c|}
\hline ADOLESCENTES & IDOSAS \\
\hline $\begin{array}{l}\text { 1. Data de Nascimento: } \\
\text { 2. Local de Moradia: } \\
\text { 3. Escola em que estuda: } \\
\text { 4. Série a que pertence: } \\
\text { 5. Qual matéria mais gosta? } \\
\text { 6. Qual matéria menos gosta? } \\
\text { 7. Como costumam ser suas notas? } \\
\text { 8. Tem algum problema de saúde? Qual (is)? } \\
\text { 9. Tem o hábito de jogar? Que ti po de jogo? } \\
\text { 10. Usa bebida alcoólica ou outras drogas? }\end{array}$ & $\begin{array}{l}\text { 1. Data de Nascimento: } \\
\text { 2. Local de Moradia: } \\
\text { 3. Está aposentada? } \\
\text { 4. Tem algum outro trabalho/atividade no } \\
\text { momento? } \\
\text { 5. Tem algum problema de saúde? Qual (is)? } \\
\text { 6. Estudou até que série? } \\
\text { 7. Qual matéria mais gostava? } \\
\text { 8. Qual matéria menos gostava? } \\
\text { 9. Tem o hábito de jogar? Que tipo de jogo? } \\
\text { 10. Usa bebida alcoólica ou outras drogas? }\end{array}$ \\
\hline
\end{tabular}

\section{ETAPA 2}

Nesta etapa foi introduzido o jogo Quoridor, que foi inventado por um italiano chamado Mirko Marquesi, com o nome de Pinko Pallino. ${ }^{26}$ No Brasil, ele recebeu o nome de Barreiras ou Curral.

O jogo Quoridor é formado por tabuleiro em madeira, com quatro peões e 20 barreiras. Ganha o participante que atingir em primeiro lugar qualquer casa na linha oposta a sua linha de partida. No início as barreiras estão colocadas atrás da linha de partida de cada jogador, sendo dez barreiras para cada jogador (duas pessoas), sete barreiras para cada jogador (três pessoas), ou cinco barreiras para cada jogador (quatro pessoas). Cada um dos jogadores escolhe deslocar o seu peão ou colocar uma das barreiras. Os peões deslocam-se de uma em uma casa horizontal ou verticalmente, para frente, para trás ou para os lados, mas nunca na diagonal. As barreiras devem ser contornadas, ou seja, não se pode pular sobre elas, que devem ser colocadas exatamente entre duas casas. A colocação das barreiras não pode fechar totalmente o acesso à linha de chegada do adversário. Quando dois peões se encontram face a face em casas vizinhas não separadas por barreiras, o jogador pode saltar o peão do adversário. Não se pode pular dois peões de uma vez, no caso de estarem jogando três ou quatro pessoas. Esta pesquisa utilizou a versão para dois participantes, conforme ilustra a Figura 1. 


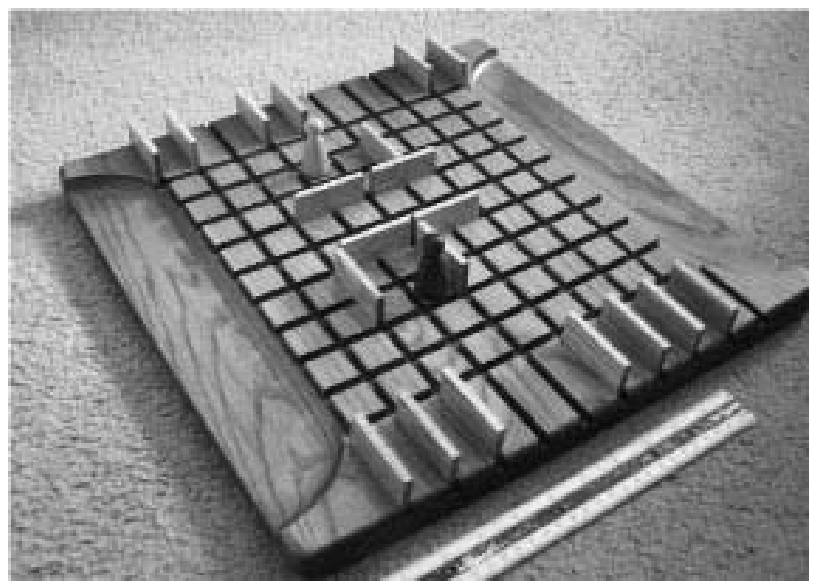

Figura 1 - Ilustração do Jogo Quoridor Fonte: Il Fogliaccio

Essa etapa teve por objetivo: (a) permitir que as participantes conhecessem o material do jogo Quoridor, seu objetivo e suas regras, ou seja, que aprendessem a jogar de maneira correta; e (b) identificar as estratégias iniciais utilizadas por elas. Cada uma das participantes jogou três partidas com a pesquisadora. Para possibilitar a análise dos dados obtidos, foram elaborados dois protocolos de registro: um referente às jogadas e o outro às estratégias.

\section{Protocolo de Registro de Jogadas}

Os registros foram realizados de acordo com os seguintes códigos:

P: peão

B: barreira

V (verde), A (amarelo): para a cor dos piões.

Exemplo de registro:

PARTICIPANTE:

DATA:

ETAPA:

ADVERSÁRIA:

- Pv A5-B5: o peão verde andou da casa A5 para a cas a B5.

- Ba D4,5 - E4,5: o adversário de cor amarela colocou uma barreira entre as casas D4 e D5 e

E4 e E5, representado na figura 2 pelo traço de cor laranja.

- Bv GH7- GH8: o adversário de cor verde colocou uma barreira entre as casas B7 e H7 e G8 e $\mathrm{H} 8$, como no exemplo da linha verde, acima. 
Protocolo de Registro de Estratégias

\begin{tabular}{|c|c|}
\hline \multicolumn{2}{|c|}{$\begin{array}{l}\text { PARTICIPANTE: } \\
\text { ETAPA: } \\
\text { ADVERSÁRIA: }\end{array}$} \\
\hline ( ) & Mover o peão para o lado sem obstáculo à frente. \\
\hline ( ) & $\begin{array}{l}\text { Colocar prioritariamente as barreiras próximas ao peão do adversário logo no } \\
\text { início do jogo, ao invés de mover o peão em direção ao seu objetivo. }\end{array}$ \\
\hline ( ) & $\begin{array}{l}\text { Colocar as barreiras aleatoriamente, sem fazer labirintos. } \\
\text { Fazer labirintos para o adversário. }\end{array}$ \\
\hline ( ) & Fazer labirintos e concluir a jogada, fechando o adversário. \\
\hline ( ) & $\begin{array}{l}\text { Mover prioritariamente o peão para frente, sem colocar inicialmente as } \\
\text { barreiras (princípio da economia das barreiras). }\end{array}$ \\
\hline ( ) & $\begin{array}{l}\text { Impedir a própria passagem, para controlar que o adversário não o faça quando } \\
\text { lhe convier. }\end{array}$ \\
\hline
\end{tabular}

Após o término das partidas, foi realizada uma entrevista, composta das questões abaixo. A entrevista pretendeu verificar o conhecimento das participantes em relação ao material, objetivos e regras do jogo Quoridor.

1. De que é composto o jogo Quoridor? Qual o material do jogo, seus componentes, suas peças?

2. Qual o objetivo do jogo? Quem ganha?

3. Quais são as regras do jogo?

4. Para que servem os peões? O que não podem fazer?

5. Quais as posições que as barreiras não podem ocupar? 


\section{ETAPA 3}

O objetivo desta etapa foi proporcionar às participantes condições para a prática no jogo. No encontro, denominado de campeonato, as participantes jogaram várias partidas com adversárias de uma mesma faixa etária.

\section{ETAPA 4}

O objetivo desta etapa era propor quatro situações-problema a cada uma das participantes, que serão apresentadas em seguida:

\section{SITUAÇÃO-PROBLEMA 1}

Essa situação prioriza a avaliação das seguintes estratégias: (1) conhecimento dos objetivos do jogo; (2) princípio da economia das barreiras para ganhar.

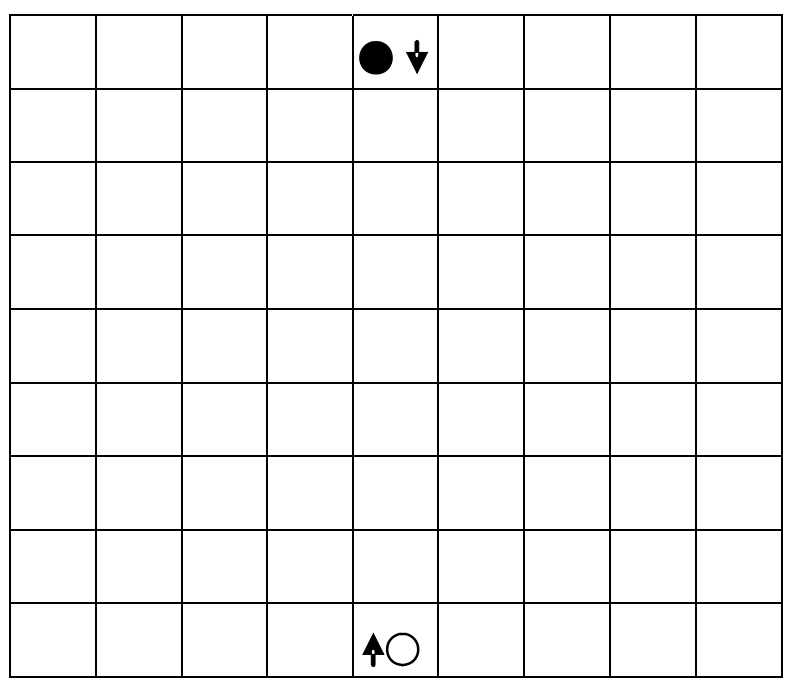

- Está no começo do jogo. É a vez do jogador preto. Quais estratégias ele poderia utilizar para começar? Por quê?

- Caso o participante não mencionasse a estratégia de economia das barreiras, era feita nova pergunta:

- É melhor avançar ou colocar as barreiras? Por quê?

Figura 2 - Ilustração da Situação-Problema 1 


\section{SITUAÇÃO-PROBLEMA 2}

Esta situação prioriza a avaliação da seguinte estratégia: utilização eficaz das barreiras, de modo a fechar adequadamente o adversário. Isso implica capacidade de coordenar ações e fazer antecipações.

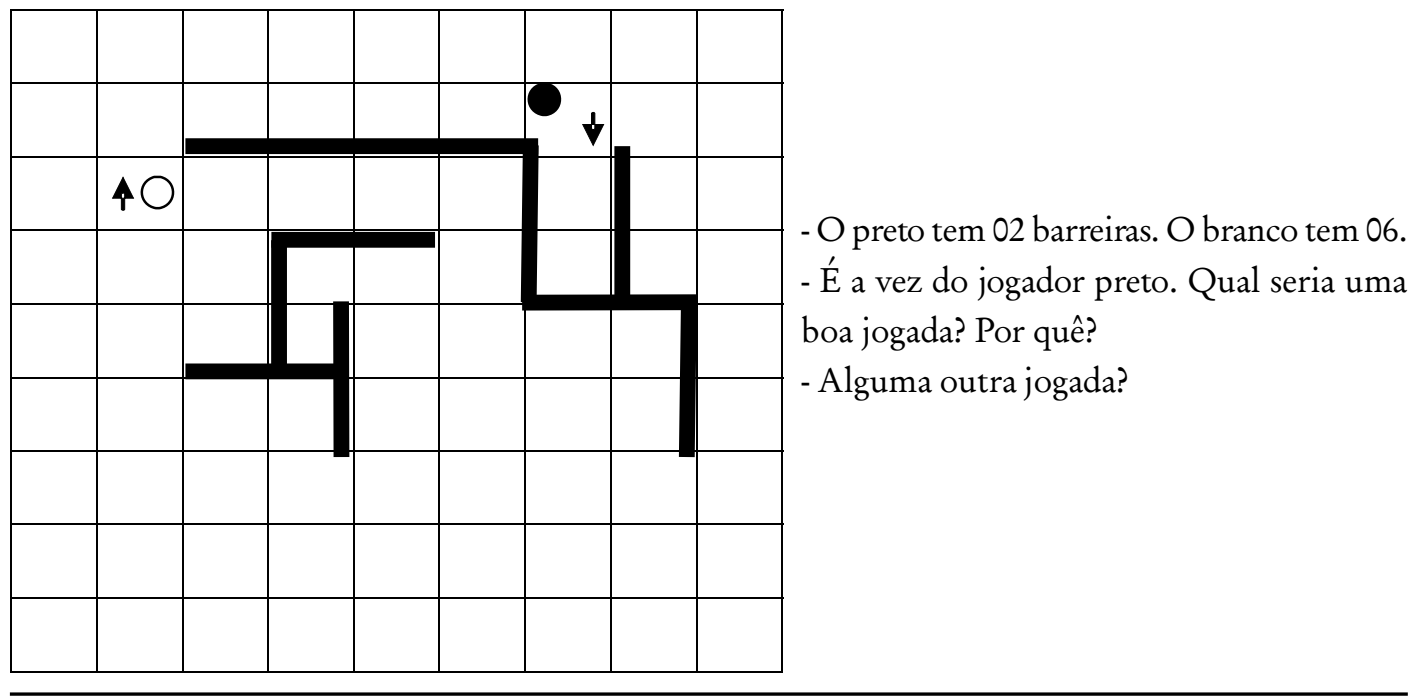

Figura 3 - Ilustração da Situação-Problema 2

\section{SITUAÇÃO-PROBLEMA 3}

Esta situação prioriza a avaliação das seguintes estratégias: (1) coordenação de ações; (2) percepção das estratégias do adversário, que está com possibilidade de realizar uma jogada de ataque.

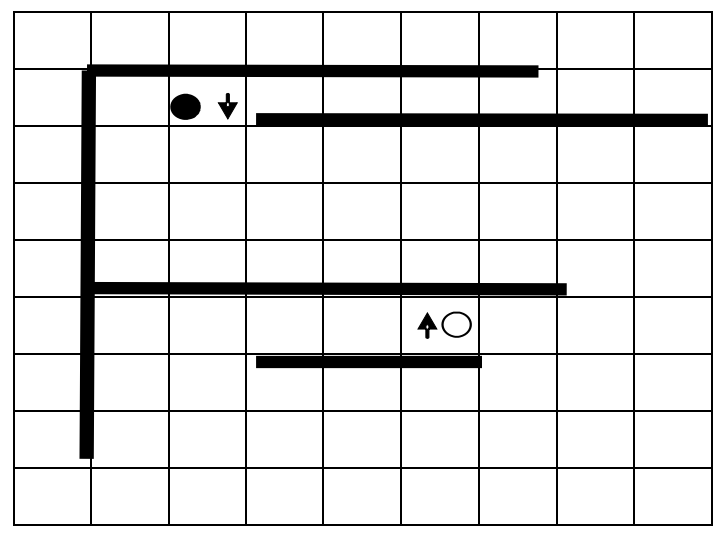

- O jogador preto tem 3 barreiras, e o branco tem 5 . - É a vez do jogador preto. Qual seria uma boa jogada? Por quê?

Caso o participante encontrasse como alternativa utilizar as barreiras, se fazia uma nova pergunta:

- Por que andar com o peão preto não é uma boa opção?

Figura 4 - Ilustração da Situação-Problema 3 


\section{SITUAÇÃO-PROBLEMA 4}

Esta situação prioriza a avaliação das seguintes estratégias: (1) princípio de economia de barreiras; (2) visão geral da utilização das barreiras.

Lugar de saída do jogador branco (ele está, no momento, com 06 barreiras)

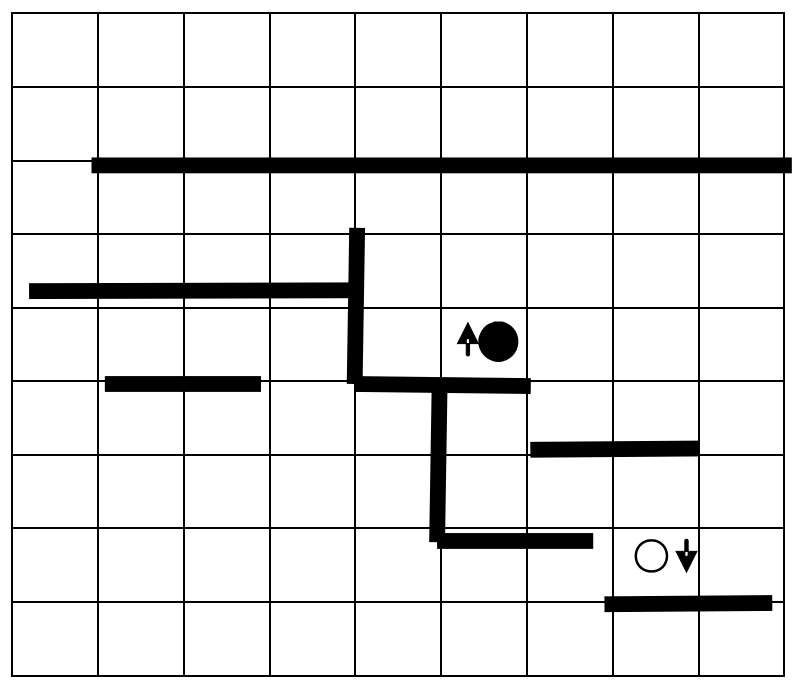

- Qual jogador tem mais chance de vencer? Por quê?

- O que o jogador preto poderia fazer para não ficar tão longe da linha de chegada?

- Como você considera que os dois jogadores usaram suas barreiras?

- Numa próxima partida, qual dica você pode dar ao jogador vermelho para melhorar seu desempenho?

Lugar de saída do jogador branco (ele está, no momento, com 01 barreira)

Figura 5 - Ilustração da Situação-Problema 4

Critérios para análise dos dados

Os níveis que serão apresentados a seguir foram elaborados com base no estudopiloto:

Nível I: demonstra, ao ser questionado, conhecimento sobre as regras do jogo. Conhece a finalidade do peão, mas o movimenta aleatoriamente. Menciona que o objetivo do jogo é chegar do lado oposto ao da linha de partida, mas não o faz na prática.
Estratégias do Nível I: (a) percebe claramente a função do peão, mas o move para os lados sem ter nenhum obstáculo à frente. Até o momento não foram observadas jogadas desse tipo que fossem eficazes, ou seja, que servissem de auxílio para se vencer uma partida; (b) conhece a função das barreiras e as coloca aleatoriamente, por exemplo, no meio do tabuleiro, distante de qualquer peão. A intenção parece ser, na maioria das vezes, de criar obstáculos futuros, mas como são colocados com antecedência, dão chance ao adversário de evitá-los com mais facilidade. 
Nível II: conhece as regras do jogo, usa as barreiras com certa coerência, tentando evitar o avanço do adversário e, às vezes, fazendo-o voltar, porém ainda não consegue perceber todos os usos das barreiras em relação a si mesmo e ao outro.

Esse nível se subdivide em dois:

Estratégias do Nível II/A: (a) cria labirintos para atrasar o adversário, mesmo que, por vezes, não chegue a concluir a estratégia; (b) anda sempre em direção à linha de chegada.

Estratégias do Nível II/B: (a) utiliza as barreiras em todas as posições, fazendo com que o adversário retorne; (b) percebe que o número de barreiras influencia o resultado do jogo, mas nem sempre encontra estratégias para economizá-las; (c) fecha o labirinto a tempo de concluir a jogada e atrasar o adversário.

Nível III: demonstra a noção de economia das barreiras, de utilização das barreiras fechando a si próprio, de forma a controlar as jogadas. Antecipa as ações do adversário, considera a interferência do adversário uma variável importante para ganhar uma partida e coordena suas ações e as do adversário.

Este nível também se subdivide:

Estratégias do Nível III/A: (a) fecha os labirintos estrategicamente e no tempo correto, de forma a fazer o adversário despender ainda mais tempo. No nível anterior, esse fechamento nem sempre acontece no melhor momento, o que permite supor que as antecipações ainda não estão completamente presentes; (b) consegue uma visão global do tabuleiro e das jogadas possíveis. Por isso, às vezes entende que determinada jogada é necessária para não haver prejuízos maiores, por exemplo, percebe que se não andar, naquele momento, o adversário poderá fechá-lo (como no caso da situação-problema 3).

Estratégias do Nível III/B: (a) fecha a si próprio para impedir que o adversário o faça quando lhe convier; (b) conhece a necessidade de economizar barreiras e consegue fazê-lo estrategicamente durante a partida; (c) percebe que é mais vantajoso deixar o adversário sair primeiro, porque no meio do tabuleiro poderá pular sobre ele e adiantar uma casa.

\section{RESULTADOS E DISCUSSÃO}

Os resultados serão apresentados de forma separada, em dois tópicos: um para o grupo das idosas e outro para o grupo das adolescentes. Será descrito um estudo de caso de cada grupo para exemplificar a análise realizada.

\section{a. Grupo das Idosas - O Caso Zuleide}

Zuleide foi a participante idosa com menor escolaridade $-7^{\mathrm{a}}$ série do ensino fundamental. Trata-se aqui apenas de um registro da escolaridade formal, mas não se podem desconsiderar todas as outras atividades dessa participante. Ela demonstra ter uma vida socioeconômica que permite atender a suas necessidades básicas, alega ter boa saúde e assume muitos compromissos em sua igreja, sendo responsável por vários projetos. 
Joga cartas semanalmente com um grupo de amigos. Sua casa fica em uma rua tranquila, onde todos se conhecem.

Quanto à compreensão do jogo, os resultados mostraram que Zuleide evoluiu do nível I para o nível III/A. Assim, nas três primeiras partidas ela se manteve no nível I, andando para os lados, colocando barreiras aleatoriamente, sem economizálas. No campeonato, começou a evoluir sua compreensão do jogo. Passou a fazer labirintos de forma mais estratégica, fechando no final. Também começou a fazer antecipações.

Zuleide ganhou quatro das cinco partidas que jogou no campeonato. Era citada pelas outras participantes como a que "jogava bem". Foi a única na quarta etapa, entre idosas e adolescentes, a responder e a justificar corretamente a situação-problema 3 , em que precisaria andar com o peão para não ser fechada pela adversária.

Ao responder e argumentar corretamente todas as situações-problema ela de- monstrou: (1) conhecimento dos objetivos do jogo; (2) utilização do princípio da economia das barreiras para ganhar a partida, fechando de maneira eficaz o adversário; (3) coordenação de ações; (4) percepção das estratégias do adversário, quando este está com possibilidade de realizar uma jogada de ataque e (5) visão geral da utilização das barreiras, seja por economia, seja por adequação de colocação. Este grau de antecipação e coordenação de ações indica um nível III/A.

Evolução do nível de compreensão do jogo Quoridor: comparação entre as idosas

Comparando os resultados obtidos pelas idosas, observou-se que três delas conseguiram evoluir: Cândida do nível I para o II/B; Cíntia do II/A para o II/B; Zuleide do I para o III/A. Diferentemente dessas três participantes, Lílian não apresentou evolução ao longo da pesquisa.

Quadro 1 - Comparação da evolução do nível de compreensão das idosas

\begin{tabular}{|l|c|c|}
\hline \multicolumn{3}{|c|}{ Compreensão do Jogo } \\
\hline Participante & Nível inicial & Nível alcançado \\
\hline Cândida & I & II/B \\
\hline Cíntia & II/A & II/B \\
\hline Lílian & I & I \\
\hline Zuleide & I & III/A \\
\hline
\end{tabular}


Desse modo, houve entre as idosas uma grande diferenciação no percurso de aprendizado do jogo. A participante que atingiu, já na primeira partida, um nível maior, não foi a que alcançou o maior nível ao final da pesquisa. Outro exemplo é Zuleide que, embora tenha começado no mesmo nível que as demais, foi a única a atingir o nível III/A. Desse modo, pode-se dizer que o nível inicial de evolução não é preditivo do nível que será alcançado depois de ter oportunidade de praticar o jogo.

A hipótese que se admite é de que em uma avaliação não se pode correlacionar o desempenho no início das atividades com o desempenho depois de um tempo de aprendizado.

Cândida começou no nível I e atingiu nível II/B. É relevante, nesta participante, o fato de haver verbalizado vários comentários negativos sobre si mesma, por exemplo: “eu não vou conseguir, nunca joguei esse jogo”. Em uma intervenção mais prolongada, os aspectos afetivos precisariam ser trabalhados, pois, neste caso, por exemplo, há indícios de que a auto-imagem pode ter comprometido seu desempenho.

O dado que mais chama a atenção é que três participantes conseguiram evoluir, excetuando Lílian, que a partir da segunda etapa da pesquisa passou por problemas familiares, além de ter adoecido. Tais variáveis precisam ser consideradas em estudos futuros, visto que há indícios de que a qualidade de vida de fato interfere na cognição.

\section{b. Grupo das adolescentes - O Caso Natália}

Natália foi a única participante adolescente que cursou o ensino fundamental em uma escola particular, mas se transferiu para uma institução pública contra a vontade da família. Ela alegou que não "gosta de estudar" e que preferia a escola em que estava.

No que se refere à compreensão do jogo, os resultados permitiram constatar que $\mathrm{Na}-$ tália evoluiu do nível I para o nível II/B, conforme os critérios de análise expostos anteriormente. Deste modo, no início da primeira partida ela usou barreiras aleatoriamente, ou seja, colocava-as de forma ineficaz no tabuleiro, sem conseguir atrasar o peão adversário. Também moveu peões para o lado, estratégia que indica não estar considerando o objetivo final do jogo, que é chegar do lado oposto ao da linha de partida. Não economizou as barreiras, muitas vezes deixando de andar com o peão para colocá-las aleatoriamente. Entretanto, demonstrou observar as jogadas da pesquisadora, fazendo labirintos, o que indica que começava a compreender que essa era uma estratégia importante para ganhar o jogo. Apesar disso, ainda não demonstrava ter compreendido como concluir a estratégia, não sendo eficaz. É preciso lembrar que essas observações dizem respeito apenas à primeira partida de um jogo que ela não conhecia. Portanto, já era de se esperar que ela demonstrasse desconhecimento das estratégias. 
A partir da quarta partida, já demonstrava uma evolução ao utilizar estratégias, conseguindo fazer, em algumas jogadas, com que o adversário voltasse através do uso de labirintos.

No campeonato, ganhou 10 das 15 partidas. Assim como Diana, outra adolescente, ela observou a importância na colocação das barreiras, mas não sua economia.

A respeito das situações-problema, que permitiram identificar quais estratégias a participante conhecia, Natália demonstrou ter bom conhecimento dos objetivos do jogo, além de perceber que a forma de utilizar as barreiras poderia ter relação com seu desempenho, e que utilizá-las seria um modo de fechar de forma eficaz o adversário. Essa estratégia ela só mencionou na última etapa. Embora tenha demonstrado avanço, não conseguiu coordenar ações de forma eficaz para perceber todas as possibilidades de jogadas, como exige a situaçãoproblema 3. Na situação-problema 4, ela menciona a importância das barreiras, mas não especifica o porquê.
Vale destacar que depois de expor a participante às situações-problema, que é a última etapa, ela demonstrou ter avançado em relação ao conhecimento do sistema lógico do jogo. Esse dado sugere que a formulação de desafios pode permitir um avanço nos meios utilizados, favorecendo uma evolução no nível de compreensão do jogo.

Evolução do nível de compreensão do jogo Quoridor: comparação entre as adolescentes

Comparando os resultados obtidos pelas adolescentes em relação à compreensão do jogo, verificou-se, como pode ser observado no Quadro 2, que todas elas conseguiram evoluir. Enquanto Ana e Quênia passaram do nível I para o II/A, Natália foi do nível I para o II/B. Diana, por sua vez, iniciou no nível II/A, alcançando o II/B.

Quadro 2 - Comparação da evolução do nível de compreensão das adolescentes

\begin{tabular}{|l|c|c|}
\hline \multicolumn{3}{|c|}{ Compreensão do Jogo } \\
\hline Participante & Nível inicial & Nível alcançado \\
\hline Ana & I & II/A \\
\hline Diana & II/A & II/B \\
\hline Natália & I & II/B \\
\hline Quênia & I & II/A \\
\hline
\end{tabular}


O fato de Ana e Quênia terem atingido o nível II/A indica que criaram labirintos para atrasar o adversário e caminharam em direção à linha de chegada, o que demonstra compreensão das regras do jogo e um início de construção de estratégias.

Enquanto Natália começou no nível I, Diana iniciou, já na primeira partida, no nível II/A, aparentando em alguns momentos repetir as jogadas da pesquisadora. Apesar disso, ambas alcançaram o mesmo nível (II/B), o que denota que conseguiram utilizar as seguintes estratégias: (1) utilizar as barreiras em todas as posições, fazendo com que o adversário retorne; (2) perceber que o número de barreiras influencia o resultado do jogo, apesar de por vezes não perceber como economizá-las; (3) fechar o labirinto a tempo de concluir a jogada e atrasar o adversário.

Pode-se observar que todas as adolescentes evoluíram na compreensão do sistema lógico do jogo. Estudos indicam que pesquisas com jogos de regras tendem a proporcionar tal evolução. Ortega e Pylro ${ }^{27}$ realizaram uma análise microgenética do NCJ com quatro estudantes de 16 anos, utilizando o jogo Quarto, e constaram que houve evolução nas explicações das estratégias.
Torres ${ }^{28}$ também obteve o mesmo resultado quando, por meio de um processo de intervenção, trabalhou dois semestres letivos com adolescentes, por meio de oficinas utilizando o jogo Rummikub, entre outros instrumentos. Ela observou uma evolução nos estádios de desenvolvimento. Esse resultado indica que a evolução na compreensão de jogo sugere um desenvolvimento que pode ser aplicado a outras situações da vida do sujeito.

Desta forma, o jogo de regras parece permitir evolução do NCJ e o desenvolvimento cognitivo em adolescentes, mostrando-se um instrumento eficaz não apenas para pesquisas transversais, mas também longitudinais, por meio de intervenção.

Comparação do nível de compreensão do jogo alcançado pelas idosas e adolescentes

Pode-se observar uma diversificação nos resultados, como mostra o Gráfico 1: (1) uma idosa não evoluiu, ficando no nível I; (2) duas adolescentes alcançaram o nível de compreensão do jogo II/A; (3) duas adolescentes e duas idosas atingiram o nível II/B; (4) Uma outra idosa atingiu o nível III/A. 
Gráfico 1 - Comparação dos níveis de compreensão do jogo alcançados pelas adolescentes e idosas

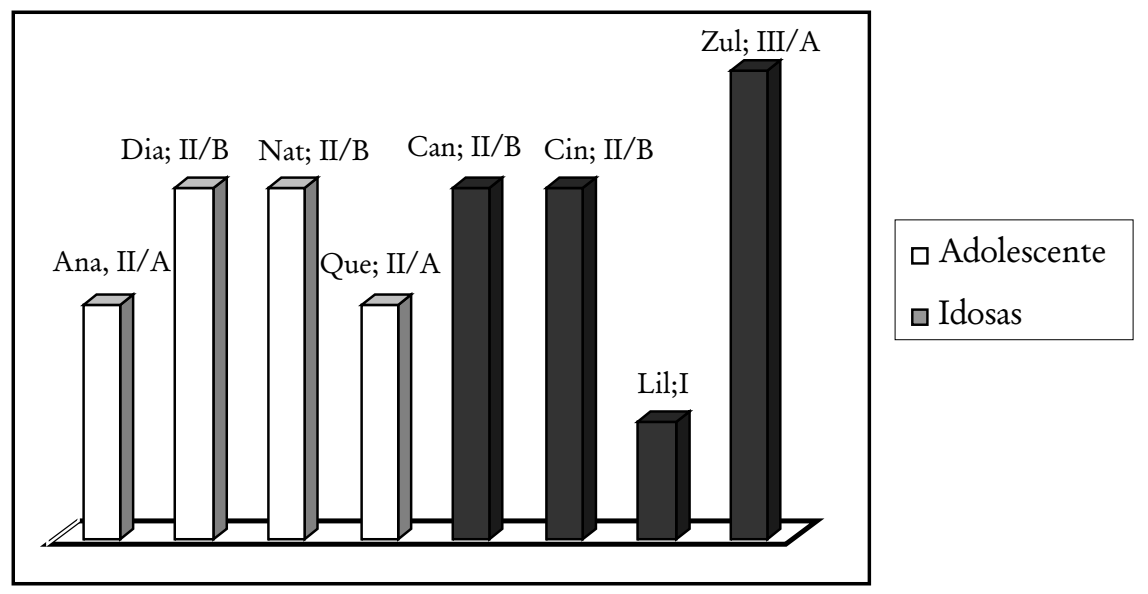

Esses dados contrariam o pressuposto de que o declínio cognitivo é inevitável em idosos jovens, e que um idoso sempre terá desempenho pior que um adolescente. Em se tratando de aspectos cognitivos, muitos são os fatores envolvidos, e apenas a faixa etária não garante uma previsão do quanto um sujeito pode se desenvolver.

Os resultados são coerentes com a visão de Neri ${ }^{29}$ e de Schaie. ${ }^{9,10}$ Os autores tomam o declínio cognitivo como inevitável, mas caracterizado por uma variabilidade individual multideterminada por fatores genéticos e ambientais. A idosa que obteve o melhor resultado tem condições de vida que incluem socialização, bem-estar e nível socioeconômico estável. Tais aspectos biopsicossociais podem influenciar a saúde em geral e o funcionamento cognitivo. As participantes idosas e adolescentes seguiram percursos que parecem ter mais relação com condições pessoais relacionadas ao estilo de vida do que com a faixa etária, visto que os níveis alcançados foram variados. Para essas participantes, a faixa etária não foi preditiva de resultados.

Os resultados encontrados se assemelham aos de Schneider. ${ }^{12}$ Essa autora utilizou um referencial teórico diferente do utilizado nesta investigação - a psicologia cognitiva. Ela objetivava comparar a tomada de decisão de dois grupos, 42 adultos jovens, entre 20 e 31 anos e 42 idosos, entre 61 e 78 anos. Utilizou uma versão adaptada de uma atividade denominada Tarefa do Jogo, que compreende uma série de escolhas monetárias, constituindo-se em uma tarefa de decisão sob incerteza. Também utilizou o jogo Torre de Hanói, entre outros instrumentos. Ela não encontrou diferenças, entre os 82 sujeitos pesquisados, em relação à idade, no tocante à tomada de decisão. 
Da mesma forma, nesta pesquisa encontraram-se semelhanças entre os resultados das adolescentes e das idosas. Os dados apontam para o fato de que o equilíbrio emocional, a realização de atividades que permitam socialização, as condições gerais de vida e a influência genética, como alerta Piaget, parece ter relevante influência nos aspectos cognitivos.

Algumas questões se colocam a partir dos resultados encontrados: é possível minimizar o declínio cognitivo? Quais métodos de intervenção serão mais eficazes para alcançar tal propósito? Tais métodos funcionariam da mesma maneira em idosos jovens saudáveis e em idosos com algum grau de demência? Se o jogo de regras for um instrumento mediador de intervenção, bastaria sua prática espontânea ou será necessária uma intervenção direcionada?

É importante considerar que os idosos são mais propensos a doenças crônicas. A possibilidade de entender o desenvolvimento cognitivo na presença de interferências orgânicas severas pode auxiliar na manutenção e melhora na qualidade de vida, a partir do pressuposto de que momentos lúdicos podem melhorar não apenas aspectos cognitivos, mas afetivos. Segundo Piaget, ${ }^{30}$ "[...] as funçôes superiores da inteligência e da afetividade tendem para um equilíbrio móvel, e tanto mais estável quanto mais móvel, de maneira que, para as mentes sãs, o fim do crescimento de modo algum marca o começo da decadência, antes permite um progresso espiritual que nada tem de contraditório com o equilíbrio anterior."
Piaget coloca pilares importantes para a elaboração de estudos sobre o envelhecimento: a promoção de mentes sãs, a relação entre inteligência e afetividade e a constante possibilidade de equilibrações. Ainda assim, o envelhecimento é uma novidade para os estudiosos, porque é possível que o próprio envelhecer esteja se modificando a partir das novas tecnologias a que se tem acesso.

Os aspectos cognitivos são fundamentais para um desenvolvimento pleno, e precisam fazer parte dos programas de saúde pública e dos objetivos dos centros de convivência para a terceira idade. A psicologia precisa investir mais nos estudos sobre cognição no envelhecimento, por meio das áreas de educação, desenvolvimento e neuropsicologia, na busca de respostas a essa nova demanda que a sociedade coloca.

Para se ter condições de trabalhar com a velhice, é preciso, em primeiro lugar, considerar as crenças pessoais, além da dificuldade em lidar com a finitude. Este parece ser um primeiro passo para se começar a ter condições de preencher as lacunas em relação ao conhecimento desse fenômeno: o envelhecimento.

\section{NOTAS}

\footnotetext{
Doutoranda do Programa de Pós-Graduação em Psicologia da Universidade Federal do Espírito Santo. E-mail: claudimarachiste@uol.com.br

b Doutor em Psicologia pela Fundação Getúlio Vargas, RJ. Docente do Programa de Pós-Graduação em Psicologia da Universidade Federal do Espírito Santo. E-mail: acortega@terra.com.br
} 


\section{REFERÊNCIAS}

1. Instituto Brasileiro de Geografia e Estatística (IBGE), 2002. [acesso 2007 nov 28] Ministério do Planejamento, Orçamento e Gestão. Disponível em: URL: http://www.ibge.gov.br/home/ presidencia/noticias/ 25072002pidoso.shtm

2. Anstey KJ, Hofer SM, Luszcz MA. Crosssectional and longitudinal patterns of dedifferentiation in late-life cognitive and sensory function: the effects of age, ability, attrition and occasion of measurement. [acesso 2006 jan 20] J Exp Psychol 2003; 132 (3): 470-87. Disponível em: URL: http://www.apa.org/journals/ releases/xge1323470.pdf

3. Argimon FIL, Stein LM. Habilidades cognitivas em indivíduos muito idosos: um estudo longitudinal. [acesso 2006 mar 13] Cad Saude Publica 2005; 21(1).

Disponível em: URL: http:// www.scielo.br/ scielo.php?script $=$ sci arttext $\&$ pid $=$ S0102 $311 \mathrm{X} 2005000100008 \& \overline{l n g}=\mathrm{pt} \& \mathrm{nrm}=$ iso

4. Denise $\mathrm{H}$, et al. Age-related differences in the course of cognitive skill acquisition: the role of regional cortical shrinkage and cognitive resources. [acesso 2006 jan 18] Psychol Aging 2002; 17(1): 72-84.

Disponível em: URL: http:// gateway.ut.ovid.com/gw1/ovidweb.cgi

5. Díaz BE, Lozano AJ, Rodriguez VN. Características biopsicosociales en una población anciana [acesso 2006 mar 3] Rev Cubana Enferm 2003; 19(3). Disponível em: URL: http:// scielo.sld.cu/ scielo.php?script $=$ sci_pdf\&pid $=$ S086403192003000300007\&lng=es\& $\&$ rm $=$ iso\&tlng =es.

6. Flicker L, et al. Predictors of impaired cognitive function in men over the age of
80 years: results from the Health in Men Study. [acesso 2007 out 3] Age Ageing 2005; 34: 77 - 80. Disponível em: URL: http://ageing.oxfordjournals.org/cgi/ reprint/34/1/77?maxtoshow $=\& \mathrm{HITS}=10 \&$ hits $=10 \&$ RESULTFORM $\mathrm{AT}=1 \&$ author $1=$ Flicker $\% 2 \mathrm{C}+\mathrm{L}$. \&andorexacttitle $=$ and\&andorexactti tleabs $=$ and\&andorexactfulltext $=$ and \&searchid $=1 \&$ FIRSTIND

$\mathrm{EX}=0 \&$ sortspec $=$ rele vance\&volume $=34 \&$ resourcetype $=$ HWCIT

7. Gottlie MGV, et al. Aspectos genéticos do envelhecimento e doenças associadas: uma complexa rede de interações entre genes e ambiente. [acesso 2008 mar 15] Revista brasileira de geriatria e gerontologia 2007; 10(3). Disponível em: URL: http://www.unati.uerj.br/tse/ scielo.php? script $=$ sci arttext\&pid $=$ S1809$98232007000300002 \& \overline{\mathrm{l}} \mathrm{ng}=\mathrm{pt} \& \mathrm{nrm}=$ iso

8. Lövdén $M$, Ghisletta $P$, Lindenberger U. Social Participation attenuates decline in perceptual speed in old and very old age. [acesso 2006 jan 18] Psychol Aging 2005; 20(3): 423-34. Disponível em: URL: http:// gateway.ut.ovid.com/gw1/ovidweb.cgi

9. Schaie KW. Intellectual development in adulthood. In: Birren JE, Schaie KW, editors. Handbook of the psychology of aging. 4. ed. [acesso 2006 jan 18], San Diego, CA: Academic Press 1996. p. 26686. Disponível em: URL: http:// geron.psu.edu/sls/publications/ BookChJouArt.htm.

10. Schaie KW. Cognitive aging. In: Pew RW, Van Hemel SB, editors. Technology for adaptive aging.[ acesso 2006 jan 18] Washington, DC: National Academy Press 2004: 41-63. Disponível em: URL: http://geron.psu.edu/sls/publications/ BookChJouArt.htm. 
11. Schaie KW. What can we learn from longitudinal studies of adult intellectual development. [acesso 2006 jan 18] Research in Human Development 2005; 2 (3): 133-58. Disponível em: URL: http:// geron.psu.edu/sls/publications/ BookChJouArt.htm.

12. Schneider DDG. O desempenho de adultos jovens e idosos na tarefa do jogo: um estudo sobre tomada de decisão. [dissertação]. [acesso 2007 jan 28] Porto Alegre, RS: Universidade Federal do Rio Grande do Sul; 2004. Disponível em: http://www.biblioteca.ufrgs.br/ bibliotecadigital/2005-1/tese-psico459159.pdf

13. Souza PS, et al. Avaliação do desempenho cognitivo em idosos. [acesso 2008 mar 15] Revista brasileira de geriatria e gerontologia 2007; 10(1). Disponível em: URL: http://www.unati.uerj.br/tse/ scielo.php?script $=$ sci arttext\&pid $=$ S1809 $98232007000100003 \& \overline{\mathrm{l}} \mathrm{ng}=\mathrm{pt} \& \mathrm{nrm}=$ iso.

14. Stevens FCJ, et al. How ageing and social factors affect memory. [acesso 2006 jan 21] Age Ageing 1999; 28(4): 379-84. Disponível em: URL: http:// ageing.oxfordjournals.org/cgi/reprint/28/ $4 / 379$

15. Piaget J. A tomada de consciência. São Paulo: Melhoramentos; 1977.

16. Piaget J. Epistemologia genética. São Paulo: Martins Fontes; 1970.

17. Santos CC, Rossetti CB, Ortega AC. Funcionamento cognitivo de idosos e de adolescentes num contexto de jogo de regras. Revista Estudos Interdisciplinares sobre o Envelhecimento 2006; 9: 53-74.

18. Matos NM. O significado do lúdico para os idosos. [dissertação]. Brasília: Universidade Católica de Brasília; 2006.

19. Rossetti CB, Souza MTCC. Jogos de regras e cognição: uma revisão da produção de três grupos de pesquisa brasileiros. In: Queiroz SS, Ortega AC, Enumo SRF, organizadores. Desenvolvimento e aprendizagem humana: temas contemporâneos. Vitória: GM Gráfica \& Editora; 2005.

20. Prado SD, Sayd JD. A pesquisa sobre envelhecimento humano no Brasil: pesquisadores, temas e tendências. [acesso 2006 jan 20] Ciência Saúde Coletiva 2004; 9(3): 763-72. Disponível em: http://www.scielo.br/ scielo.php? pid $=$ S1413$81232004000300027 \&$ script $=$ sci_arttext\&tlng $=p t$

21. Yassuda MS, et al. Treino de memória no idoso saudável: benefícios e mecanismos. [acesso 2008 abr 2] Psicologia, Reflexão e Critica 2006; 19(3). Disponível em: URL: www.scielo.com.br

22. Meltzoff J. Research questions and hypotheses. In: . Critical thinking about research: Psychology and related fields. Washington, DC: American Psychological Association; 2001. p.13-21.

23. Piaget J. Fazer e compreender. São Paulo: Melhoramentos; 1978.

24. Resolução 196/96 do Ministério da Saúde. (1996). [acesso 2007 maio 5] Diretrizes e normas regulamentadoras de pesquisa envolvendo seres humanos. Disponível em: URL: htt://conselho.saude.gov.br/

25. Resolução 016/2000 do Ministério da Saúde. (2000). [acesso 2007 maio 5]

Diretrizes e normas regulamentadores de pesquisa envolvendo seres humanos.

Disponível em: URL: http:// conselho.saude.gov.br/

26. Il Fogliaccio degli Astratti. [acesso 2006 jan 27] Disponível em: URL: http:// www.pergioco.net/Giochi/ FogliaccioAstratti/FdA\%202 5/ FdA\%2025.html 
27. Ortega AC, Pylro SC. Análise microgenética do nível de compreensão do jogo Quarto. Luminis 2007; 2 (2): 16-31.

28. Torres MZ. Processos de desenvolvimento e aprendizagem de adolescentes em oficinas de jogos. [tese]. São Paulo: Universidade de São Paulo; 2001.
29. Neri LA, organizador. Desenvolvimento e envelhecimento: perspectivas biológicas, psicológicas e sociológicas. Campinas: Papirus; 2001.

30. Piaget J. Seis estudos de Psicologia. Lisboa: Publicações Dom Quixote; 1973.

Recebido em: 18/12/2007

Revisado: 14/4/2008

Aprovado: 05/5/2008 
1 